\title{
The nonlinear analysis of an innovative slit reinforced concrete water tower in seismic regions
}

\author{
F. Gurkalo, Y.G. Du ${ }^{\mathrm{a}}$, K. Poutos ${ }^{\mathrm{b}}$, C. Jimenez-Bescos ${ }^{\mathrm{a}}$ \\ a Department of Engineering and Built Environment, Anglia Ruskin University, Chelmsford CM1 1SQ, United \\ Kingdom \\ ${ }^{\mathrm{b}}$ School of Computing and Engineering, University of West London, London W5 5RF, United Kingdom
}

Email addresses: f.gurkalo@gmail.com (F. Gurkalo), yingang.du@anglia.ac.uk (Y.G. Du),

Konstantinos.Poutos@uwl.ac.uk (K. Poutos), Carlos.JimenezBescos@anglia.ac.uk (C. Jimenez-Bescos)

Corresponding author: F. Gurkalo (f.gurkalo@gmail.com)

\begin{abstract}
Water towers are widely used in our society as one of water distribution facilities within water network systems. In the event of a severe earthquake, however, a single plastic hinge that occurs in a water tower could cause its total collapse before nonlinear resources of the rest of the tower remains fully utilised. This research presents an innovative technique for the assembly of a water tower using the slits in its reinforced concrete shaft for the purpose of mitigating the seismic response. Slit shafts were designed to have four slits at 90 degree intervals along the full height of the shafts. The shaft parts were connected to each other at the bottom, top and every five meters with coupling beams. The slit width was used as a variable in this study which varied between $50 \mathrm{~mm}$ and $2000 \mathrm{~mm}$. The nonlinear seismic performance of the proposed slit towers was analysed by means of a finite element approach with respect to soil types defined in Eurocode 8 and seismic behaviour were compared to the solid water tower. A detailed observation of the compression and tension stress distributions with respect to the slit width was performed.
\end{abstract}

The obtained analytical results revealed that slit width in the reinforced concrete tower affect the failure mode and stiffness of a water tower significantly. With an appropriate design, the conversion of a solid water tower into a slit tower can significantly increase its ductility under seismic action without significantly compromising its bearing capacity. The results showed that contours of tension and compression stress intensity in shafts, which could lead to a failure of water towers, highly depended on the slit width. In the solid water tower, the stress 
concentration dominated at the base of the shaft, however in the narrow slit water towers the stresses were equally distributed along the height of the shafts. Also, the stresses were mostly concentrated at the top of the shafts in the wide slit water towers. Conclusively, the results provided useful information regarding the compression stress distribution along the slit shafts in the water towers which can be used in obtaining an optimum slit shaft design for different soil types.

Key words: RC water tower, nonlinear structural analysis, SAP2000, finite element analysis, seismic, earthquake, pushover, capacity spectrum

\section{Introduction}

There are a large number of water towers around the world which play an imperative role in municipal water supply and firefighting systems. Particularly, in the event of an earthquake, a water tower would become a vital lifeline and is expected to remain functional to serve, as a provider of portable water and for firefighting operations. The failure or malfunction of this essential infrastructure would disrupt the emergency response and recovery operation after an earthquake.

There have been numerous studies carried out on water tower regarding its fluid-structure interaction and seismic performance [1-3]. However, limited study has been conducted on RC shaft performance [4]. Unlike commonly constructed building structures whose actions do not vary too much during their lifetime, the actions on a water tower varies significantly whilst working in the water system. The overall weight of an empty water tower may drop to $20 \%$ of the full tank state. Such variation of the gravity load makes the seismic design of a water tower become more complicated. Furthermore, water towers do not have redundant members and therefore do not have any load redistribution path. During a strong seismic event, even if the water tank can survive, damages in the water tower itself could result in a total collapse, because of its low redundancy and poor ductility.

The poor performance of water towers in many earthquakes have been documented in literature such as; Jabalpur 1997 [5], Bhuj 2001 [6], Chile 1960 [7], and Manjil Roudbar 1990 [8]. The extent of the damages ranges from minor cracks in the tower shaft to complete collapse of the entire towers. 
Monolithic reinforced concrete (RC) water tower have relatively high load-bearing resistance and flexural stiffness. However, it does not show significant ductile behaviour. Ductile behaviour in RC water towers occurs by yielding of the flexural reinforcement in the tower shafts and development of a plastic hinge [9].

There are a number of seismic strategies to mitigate the damages on tower shaft and to prevent collapses of water towers. One is to increase the load-bearing resistance and flexural stiffness by increasing the thickness and reinforcements of a tower. However, it also increases seismic effect of the water tower due to the increase of the tower stiffness. Another is to decrease the seismic effects through energy dissipation system.

Numerous investigations have been conducted to improve the ductility of shear walls subjected to seismic loads and some practical solutions were proposed. The research aim was to reduce the energy concentration from the base of the wall and distribute it along whole height of the wall. In the early 1970 s, an improved type of the shear wall called the slit shear wall was proposed by Mutoh [10] to improve the shear wall performance against lateral forces. The slit wall showed an increase of the ductility and seismic energy dissipation due to slits and connectors between parts of the wall. Further studies by other researches revealed an increase in the ductility within the slit shear walls in comparison to normal shear walls without undermining of load-bearing resistance $[11,12]$. Although this technique has been used in shear wall, no report has been found on its use in water tower.

This paper presents an innovative system of assembling water tower using a slit wall technique for the purpose of reducing seismic effects more uniformly distributed across the shaft height, which may lead to a decreased ductility demand at the base without decline of load-bearing resistance. The proposed silt water tower is analysed using finite element method to verify its non-linear performance in an earthquake. The relevant results can be refereed to for the design of water towers in seismic zone.

\section{Solid and slit water tower}

The particular water tower configuration considered as solid model in this study is that of an actual Anjar Nagar Palika water tower which was damaged in the Bhuj earthquake that occurred on January $26^{\text {th }} 2001$ which reached a magnitude of 7.7 [13]. The tension-flexure cracks in the tower shaft were observed up to one third the height of the shaft. These cracks 
were parallel to the ground and covered the entire perimeter of the shaft. The cracks passed through the thin section of the shaft and were clearly visible from outside and inside. This damage to the staging seriously reduced its lateral load carrying capacity, increased its susceptibility to a greater damage or collapse in a repeat occurrence of such an event. Some simplifications have been done for the water tower model, however the effects of such simplification was found to have little effect on the total response. The simplified model of the Anjar Nagar Palika water tower shown in Figure 1 and other properties of the water tower are given in Table 1.

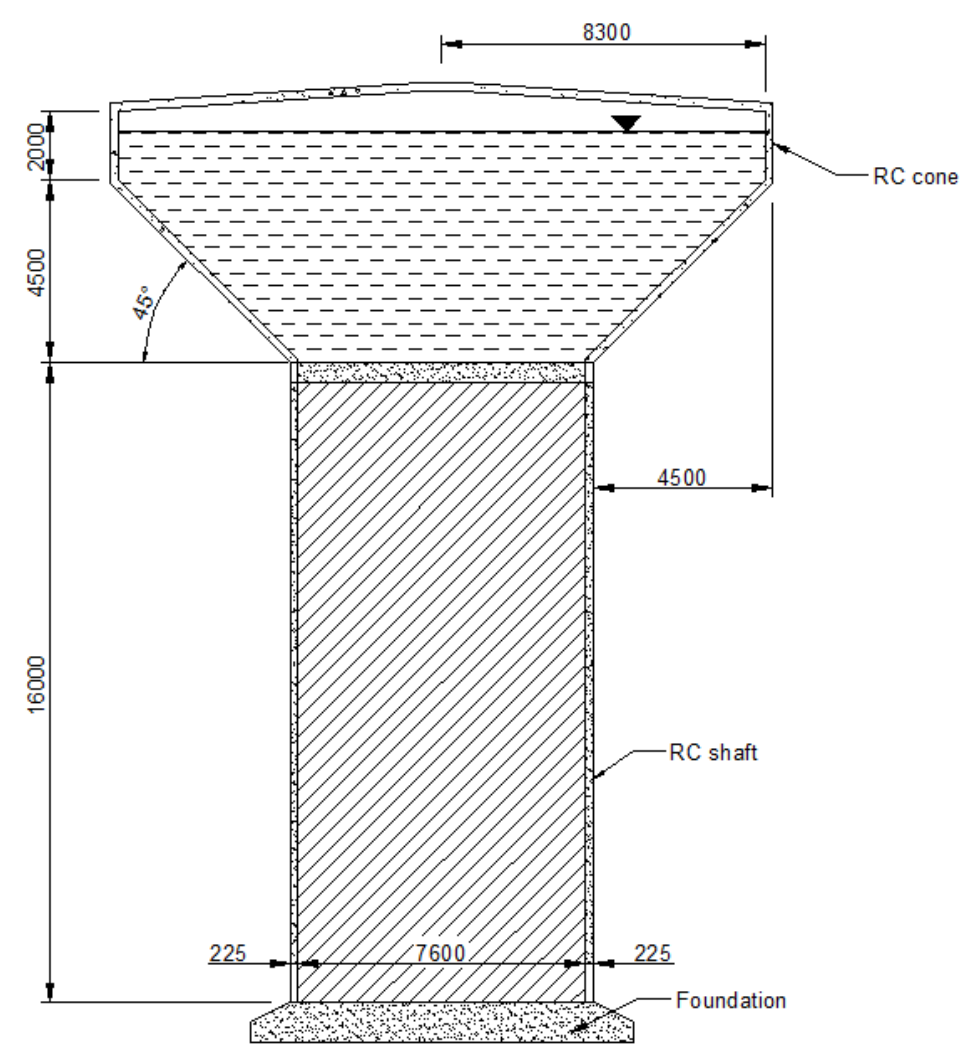

Figure 1. Simplified model of the Anjar Nagar Palika water tower.

There have been a number of studies on the effectiveness of using slit shear walls in seismic zones using finite element approach. Some researchers studied a crash and crack formation in solid and slit shear walls [14]. It was found that the slit wall dissipates seismic energy by cracks extended on all the surface of the wall and by crushing of the shear connections and the solid wall dissipates seismic energy only by cracks at the base of the wall. The other researchers studied the optimal height and steel ratio in the connectors in slit shear walls [15]. Finally, some researchers studied an optimal width and height of slits [16-17]. 
In order to investigate the effects of seismic load on the performance of slit towers, the slit width was taken as a parameter to be studied. Slit shafts were designed to have four slits at 90 degree intervals along the full height of the shaft and connected with foundation at the bottom of the shaft, beams at the height of 5 and 10 meters from the ground and the ring beam at the top of the shaft. Slits ranging from $50 \mathrm{~mm}$ to $2000 \mathrm{~mm}$ were examined in this study. The slit shaft models have the same overall dimensions and material properties as the solid shaft. The proposed model of a slit water tower is shown in Figure 2 and other properties are given in Table 1.

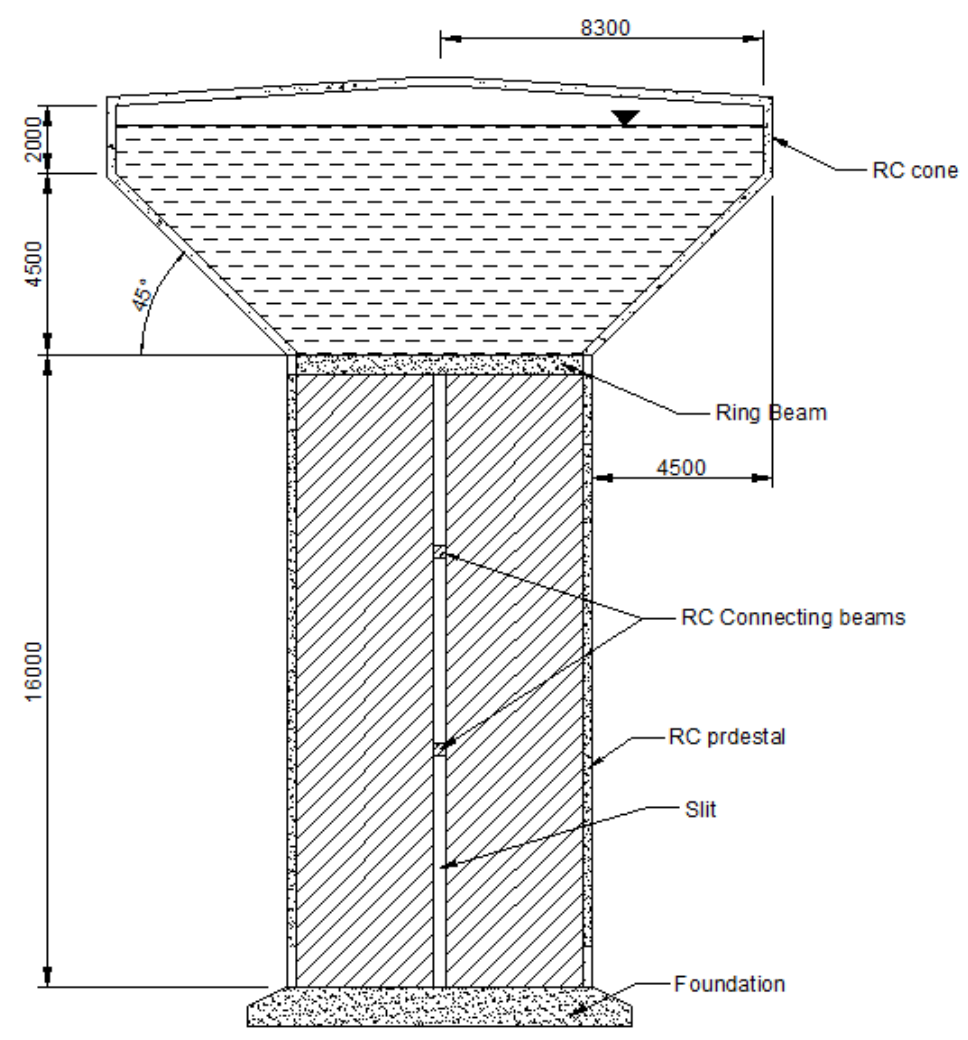

Figure 2. Proposed model of a slit water tower.

Table 1. Dimensions of water towers used in this study.

\begin{tabular}{|l|l|l|}
\hline & Solid tower & Slit tower \\
\hline Shaft diameter & $7.6 \mathrm{~m}$ & $7.6 \mathrm{~m}$ \\
\hline Shaft height & $16 \mathrm{~m}$ & $16 \mathrm{~m}$ \\
\hline Shaft wall thickness & $225 \mathrm{~mm}$ & $225 \mathrm{~mm}$ \\
\hline Tank diameter & $16.6 \mathrm{~m}$ & $16.6 \mathrm{~m}$ \\
\hline Tank height & $6.5 \mathrm{~m}$ & $6.5 \mathrm{~m}$ \\
\hline Tank wall thickness & $250 \mathrm{~mm}$ & $250 \mathrm{~mm}$ \\
\hline Tank floor thickness & $300 \mathrm{~mm}$ & $300 \mathrm{~mm}$ \\
\hline Capacity of the water tank & $1000 \mathrm{~kL}$ & $1000 \mathrm{~kL}$ \\
\hline Ring beam & $500 \mathrm{~mm} \times 225 \mathrm{~mm}$ & $500 \mathrm{~mm} \times 225 \mathrm{~mm}$ \\
\hline Connection beams & N/A & $350 \mathrm{~mm} \times 225 \mathrm{~mm}$ \\
\hline Slit width & N/A & $50 \mathrm{~mm}$ to $2000 \mathrm{~mm}$ \\
\hline Connection beam location & N/A & $5 \mathrm{~m}$ and $10 \mathrm{~m}$ from the ground \\
\hline
\end{tabular}




\section{Finite Element Model}

Generally, the RC water tower could be divided into three substructures including the water tank, shaft and foundation. However, this study was focused on the nonlinear response of the RC shaft substructure using finite element software SAP2000 [18] and therefore a number of simplifications are made for modelling of the other two substructures.

The water tank consists of the vessel and the water inside. Two mass model of water was adopted from Eurocode 8: Part 4 [19]. The Eurocode 8 suggests the uniform distribution of the impulsive mass among the nodes in a model, with the lumped masses attached directly to the wall element nodes and convective mass attached to the wall element nodes by springs. The water tank capacity was $1000 \mathrm{~m}^{3}$ ant an assumption was made that $1 \mathrm{~m}^{3}=1,000$ litres $=1,000$ $\mathrm{kg}$ thus total mass inside the water tank was assumed to be $1,000,000 \mathrm{~kg}$. An approximation of water height for calculation impulsive and convective masses of the axisymmetric tank obtained from an equivalent cylindrical tank having the same free surface diameter and an equivalent water depth was made according to Eurocode 8 recommendations. The two-mass model of water is shown in the Figure 3. This study was not focused on the nonlinear behaviour of a water tank thus the water tank was modelled using linear four-node quadrilateral thin shell elements.

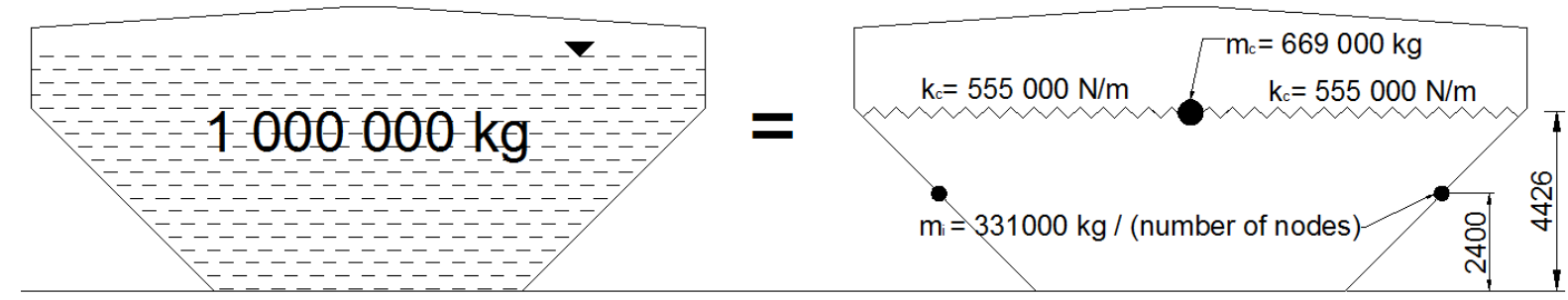

(a)

Figure 3. (a) Water tank of proposed models (b) Equivalent two mass model.

For reinforced concrete shaft design both geometric nonlinearity and material nonlinearity were considered in this study. The finite element (FE) models were modelled using the nonlinear layered four-node quadrilateral shell element defined in SAP2000, because the wall thickness of the RC shaft in water towers is significantly smaller than the shaft height and diameter. This element is able to model essential mechanical elastic and inelastic characteristics of reinforcement as concrete and steel materials separately. The proposed layered shell element is based on the principles of composite material mechanics and it can simulate the coupled in- 
plane/out-plane bending and the coupled in-plane bending-shear nonlinear behaviours of a RC shaft [20]. The multi-layer shell element is a combination of a number of layers where reinforcement and concrete was assigned separately (Figure 4). During the finite element analysis, the axial strain and curvature of the middle layer was obtained in one element. After that, according to the assumption that plane remains plane, the strains and the curvatures of the other layers were calculated. Finally, the corresponding stress was calculated through the constitutive relations of the material assigned to the layer. From the above principles, it is seen that the structural performance of the RC shaft can be directly connected with the material constitutive law. The constitutive model of the rebar was set as the perfect elasto-plastic model.

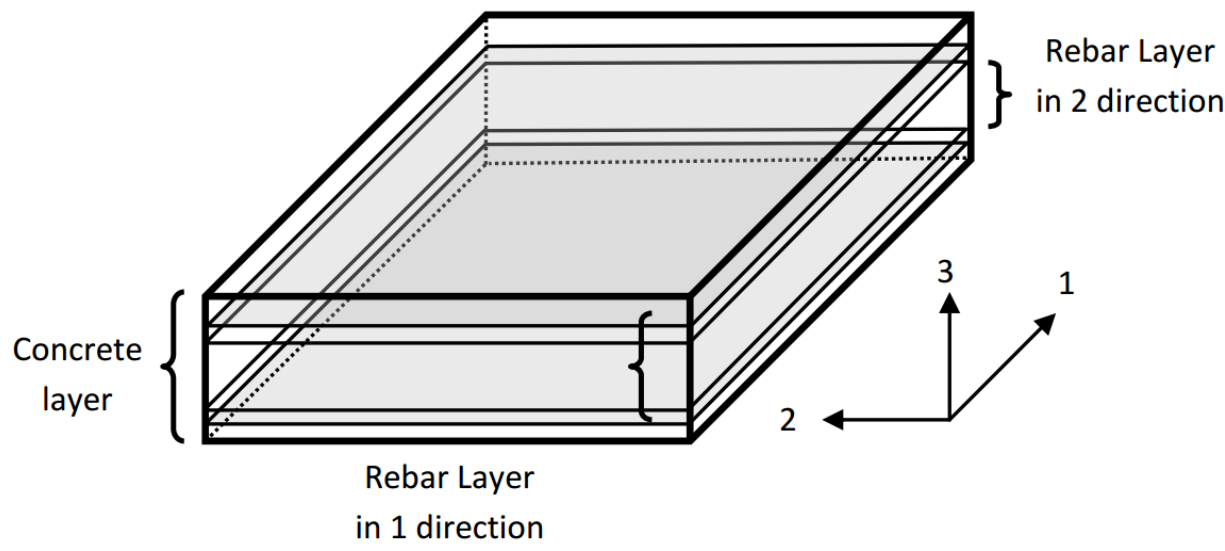

Figure 4. Layered four-node quadrilateral shell element [20].

For modelling slit water towers a beam element was introduced for connections in the slit towers. The nonlinear behaviour of beams was modelled by placing a rigid plastic spring at the location where yielding was expected. The part of a member between the two rigid plastic springs remained perfectly elastic and all inelastic deformation was assumed to occur in these springs. The nonlinear model of beams was based on plastic hinge concept and a bilinear moment-rotation relationship [21]. The fibre plastic hinges defined in SAP2000 were introduced on the plastic zones at the end of the beams. The hinge involved a process of dividing the section in multiple longitudinal fibres. In this study, for each fibre in the cross section, the material nonlinear stress-strain curve was used to define the axial stress-strain relationship. Summing up the behaviour of all the fibres in the cross section and multiplying by the hinge length gives the axial force-deformation and biaxial moment-rotation relationships. The adopted hinge length was taken as 0.5 of the beam height, according to Park and Pauley [22]. 
A nonlinear finite element modelling of reinforced concrete structures requires defining an accurate stress-strain curve for both concrete and rebar. A nonlinear analysis, examine the response of the structures up to extreme deformations in which concrete and steel material reach failure point and the structures collapse. Figure 5 shows the stress-strain models proposed by Mander [23] and Holzer [24] were selected for modelling concrete and steel rebar in this study respectively.

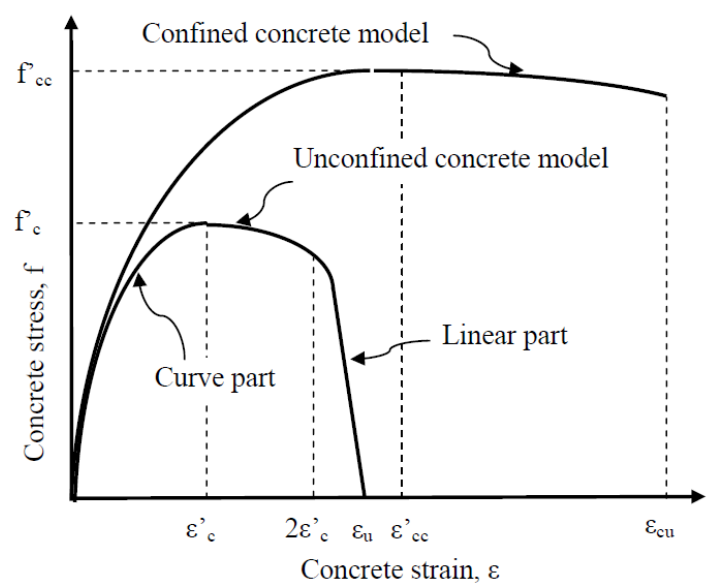

(a)

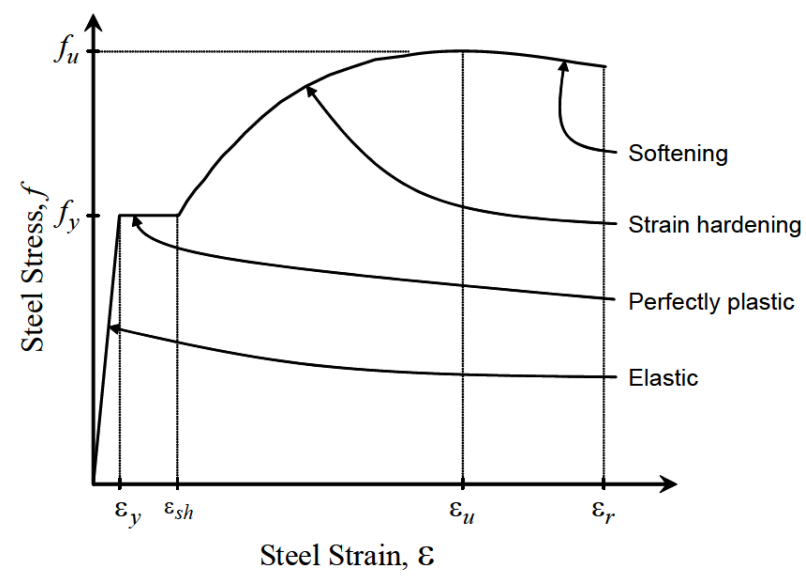

(b)

Figure 5. (a) The stress-strain concrete model [23], (b) The stress-strain rebar model [24].

The C20/25 concrete and transverse and longitudinal reinforcement in the shaft was assumed as $0.25 \%$ for the calculations with agreement to the original Anjar Nagar Palika water tower studied by Rai [13]. The stress-strain curves of concrete and rebar are presented in Figure 6 . For concrete material both compressive strength $f_{c}$ and tensile strength $f_{t}$ were taken as $-20 \mathrm{~N} / \mathrm{mm}^{2}$ and $2.79 \mathrm{~N} / \mathrm{mm}^{2}$ respectively. Both Young's Modulus and Poisson's ratio were taken as $30 \mathrm{~N} / \mathrm{mm}^{2}$ and 0.2 . Both strain at compressive strength, $\varepsilon^{\prime}{ }_{\mathrm{c}}$ and ultimate strain, $\varepsilon_{\mathrm{u}}$ as 0.00133 and 0.00383 . For reinforcement both yield strength, $f_{y}$ and ultimate strength, $f_{u}$ were taken as $414 \mathrm{~N} / \mathrm{mm}^{2}$ and $620 \mathrm{~N} / \mathrm{mm}^{2}$ respectively. Both yielding strain, $\varepsilon_{\mathrm{y}}$ and ultimate strain, $\varepsilon_{\mathrm{u}}$ as 0.00207 and 0.09 respectively. Concrete and reinforcement used in this study summarised in Table 2. 
(a)

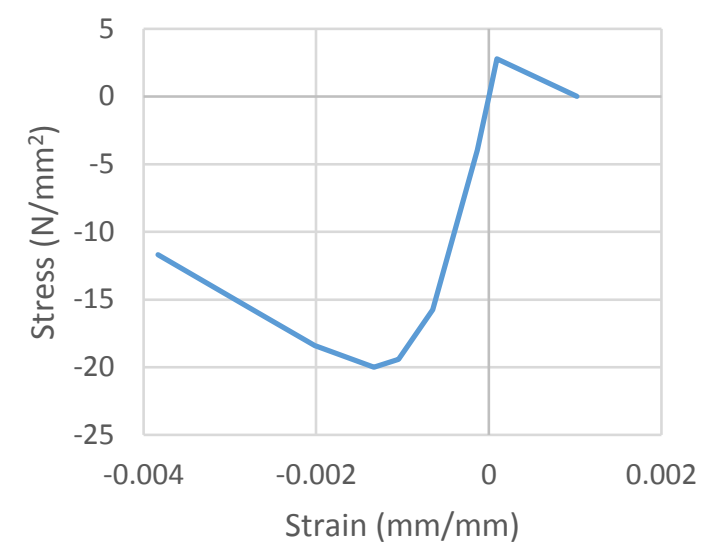

(b)

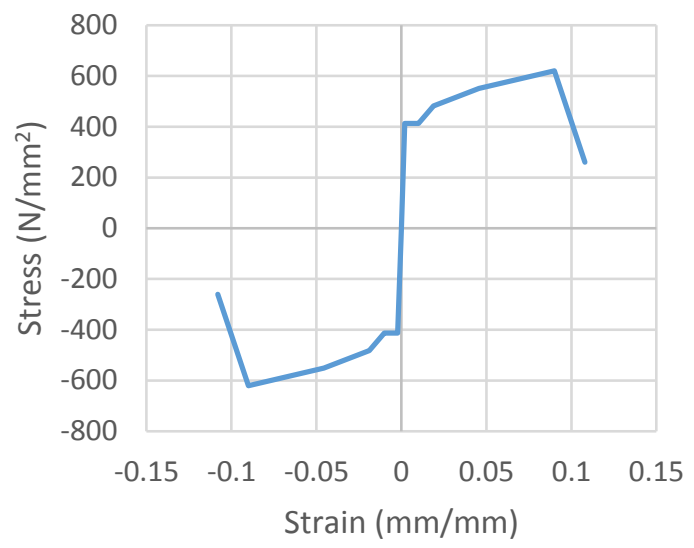

Figure 6. (a) The stress-strain C20/25 concrete model (b) The stress-strain rebar model.

Table 2. Concrete and reinforcement used in this study.

\begin{tabular}{|l|l|l|}
\hline & Solid tower & Slit tower \\
\hline Concrete & C20/25 & C20/25 \\
\hline Shaft reinforcement & $\begin{array}{l}2 \text { layers } \emptyset 10 \text { every } 275 \mathrm{~mm} \text { for } \\
\text { both transverse and longitudinal } \\
\text { reinforcement }\end{array}$ & $\begin{array}{l}\text { 2 layers } \emptyset 10 \text { every } 275 \mathrm{~mm} \text { for } \\
\text { both transverse and longitudinal } \\
\text { reinforcement }\end{array}$ \\
\hline Beam longitudinal reinforcement & $\begin{array}{l}2 \text { bars } \varnothing 25-\text { compression } \\
2 \text { bars } \emptyset 25-\text { tension }\end{array}$ & $\begin{array}{l}2 \text { bars } \emptyset 25-\text { compression } \\
2 \text { bars } \emptyset 25-\text { tension }\end{array}$ \\
\hline Beam traverse reinforcement & 2 bars $\emptyset 10$ every $150 \mathrm{~mm}$ & 2 bars $\emptyset 10$ every $150 \mathrm{~mm}$ \\
\hline
\end{tabular}

The foundation of the water tower was assumed to be rigid and shaft was fixed at the level of foundation. Boundary conditions were applied by constraining all degrees of freedom at the base level of the RC shaft. FE model of a solid model and slit model are illustrated in Figure 7. 


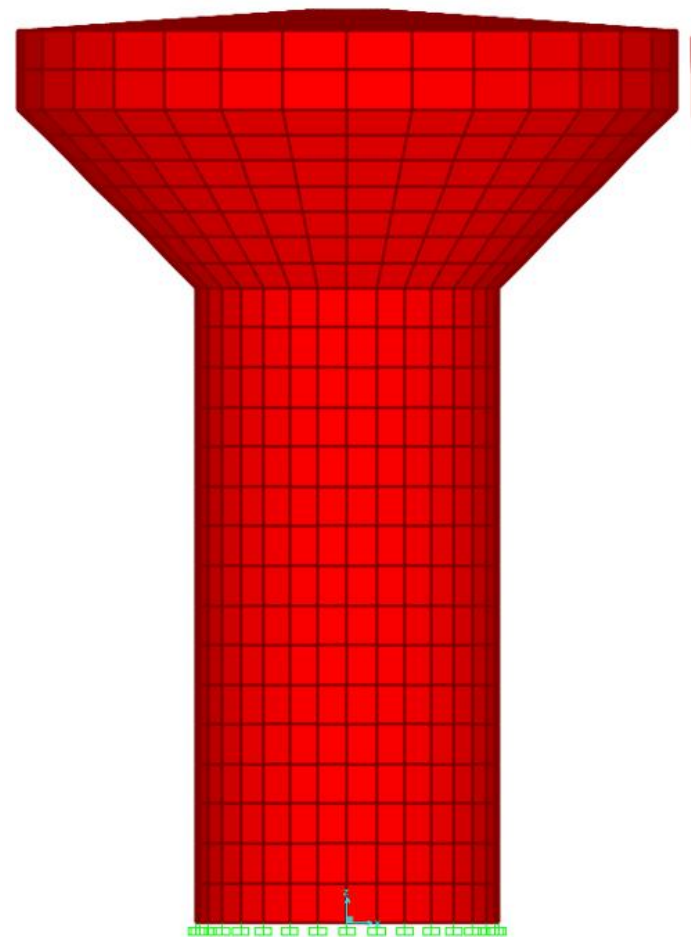

(a)

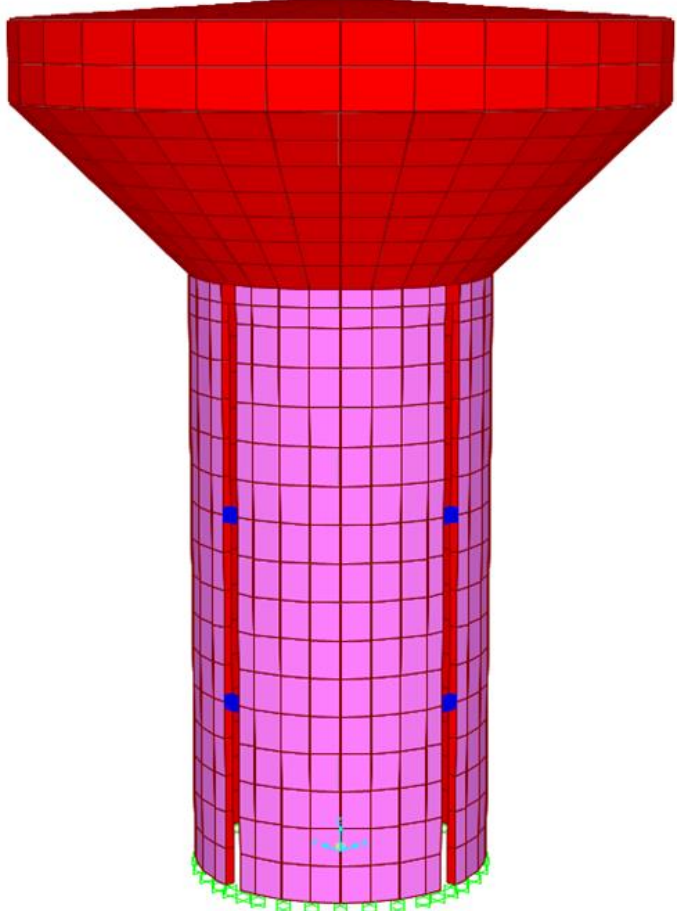

(b)

Figure 7. Finite element model of (a) Solid water tower (b) Slit water tower.

In this study the case of full tank condition was investigated because maximum base shear and top lateral displacement in RC shaft elevated water tanks usually occurred in full condition. Each FE model was assigned a finite element model identification number (FE model ID) as presented in Table 3.

Table 3. FE model ID of selected water towers.

\begin{tabular}{|l|c|}
\hline \multicolumn{1}{|c|}{ Slit width } & FE Model ID \\
\hline Solid shaft & M-0 \\
\hline Slit width $50 \mathrm{~mm}$ & M-50 \\
\hline Slit width $100 \mathrm{~mm}$ & M-100 \\
\hline Slit width $200 \mathrm{~mm}$ & M-200 \\
\hline Slit width $300 \mathrm{~mm}$ & M-300 \\
\hline Slit width $500 \mathrm{~mm}$ & M-500 \\
\hline Slit width $1000 \mathrm{~mm}$ & M-1000 \\
\hline Slit width $1500 \mathrm{~mm}$ & M-1500 \\
\hline Slit width $2000 \mathrm{~mm}$ & M-2000 \\
\hline
\end{tabular}

\subsection{Model verification}

To further verify the current FE technique, the modal analysis of the M-0 model was performed and the result of the fundamental period was compared with the value obtained by Rai [13]. The difference for the fundamental periods between FE results and Rai theoretical calculations was less than 5 percent. The fundamental period of the comparable elevated water tank 
obtained by Rai was 0.421 seconds compared to 0.441 seconds for fundamental mode obtained from FE results. The main difference in the result was due to single lumped-mass water idealisation used by Rai in comparison to two mass model water idealisation used in this study.

\section{Capacity spectrum analysis}

In this study water towers were analysed using capacity spectrum method [25], which is simple non-linear method used for calculation of structures during earthquakes. It combines multi degree pushover analysis with spectrum analysis of equivalent single degree of freedom (SDOF) system and requires that both the capacity curve (pushover curve) and the demand curve (response spectrum) to be represented in response spectral ordinates. It characterises the seismic demand initially using a 5\% damped linear-elastic response spectrum and reduces the spectrum to reflect the effects of energy dissipation to estimate the inelastic displacement demand. The point at which the capacity curve intersects the reduced demand curve represents the performance point at which capacity and demand are equal [26]. The accuracy of the method is satisfactory if a structure has dominant first mode of oscillation, such as a water tower.

The procedure of performing a pushover analysis in this study was adapted from Eurocode 8 . In case of the water tower, the lateral load was applied with a load pattern similar to the fundamental mode shape. This is due to the fact that that most of the weight was concentrated in the tank and the modal mass participation factor of the fundamental mode was approximately $90 \%$. Therefore, the effect of other mode in the load pattern was negligible. It was assumed that entire tower behaved like a vertical cantilever beam and the maximum displacement was defined at peak of base shear as this point represents the beginning of stiffness reduction.

\section{Design response spectrum to current practice}

The design spectrums were developed for a peak ground acceleration (PGA) of $0.4 \mathrm{~g}$, which is the highest PGA suggested by Eurocode 8 [27]. The water towers were assumed to be situated in the seismically active region (Type 1) and 5\% viscous damping as suggested by Eurocode 8 for RC structures was proposed. The towers were assumed to had a high importance factor of 1.5. The response spectrums were designed for different soil types in accordance to a stratigraphic profile defined in Table 4. Figure 8 represents the design spectrums for different soil types. 
Table 4. Soil types defined in Eurocode 8 [27].

\begin{tabular}{|c|l|}
\hline $\begin{array}{c}\text { Soil } \\
\text { type }\end{array}$ & Description of stratigraphic profile. \\
\hline A & Rock or other rock-like geological formation, including at most 5 m of weaker material at the surface. \\
\hline B & $\begin{array}{l}\text { Deposits of very dense sand, gravel, or very stiff clay, at least several tens of meters in thickness, } \\
\text { characterised by a gradual increase of mechanical properties with depth. }\end{array}$ \\
\hline C & $\begin{array}{l}\text { Deep deposits of dense or medium - dense sand, gravel or stiff clay with thickness from several tens } \\
\text { to many hundreds of meters. }\end{array}$ \\
\hline D & $\begin{array}{l}\text { Deposits of loose-to-medium cohesionless soil (with or without some soft cohesive layers), or of } \\
\text { predominantly soft-to-firm cohesive soil. }\end{array}$ \\
\hline
\end{tabular}

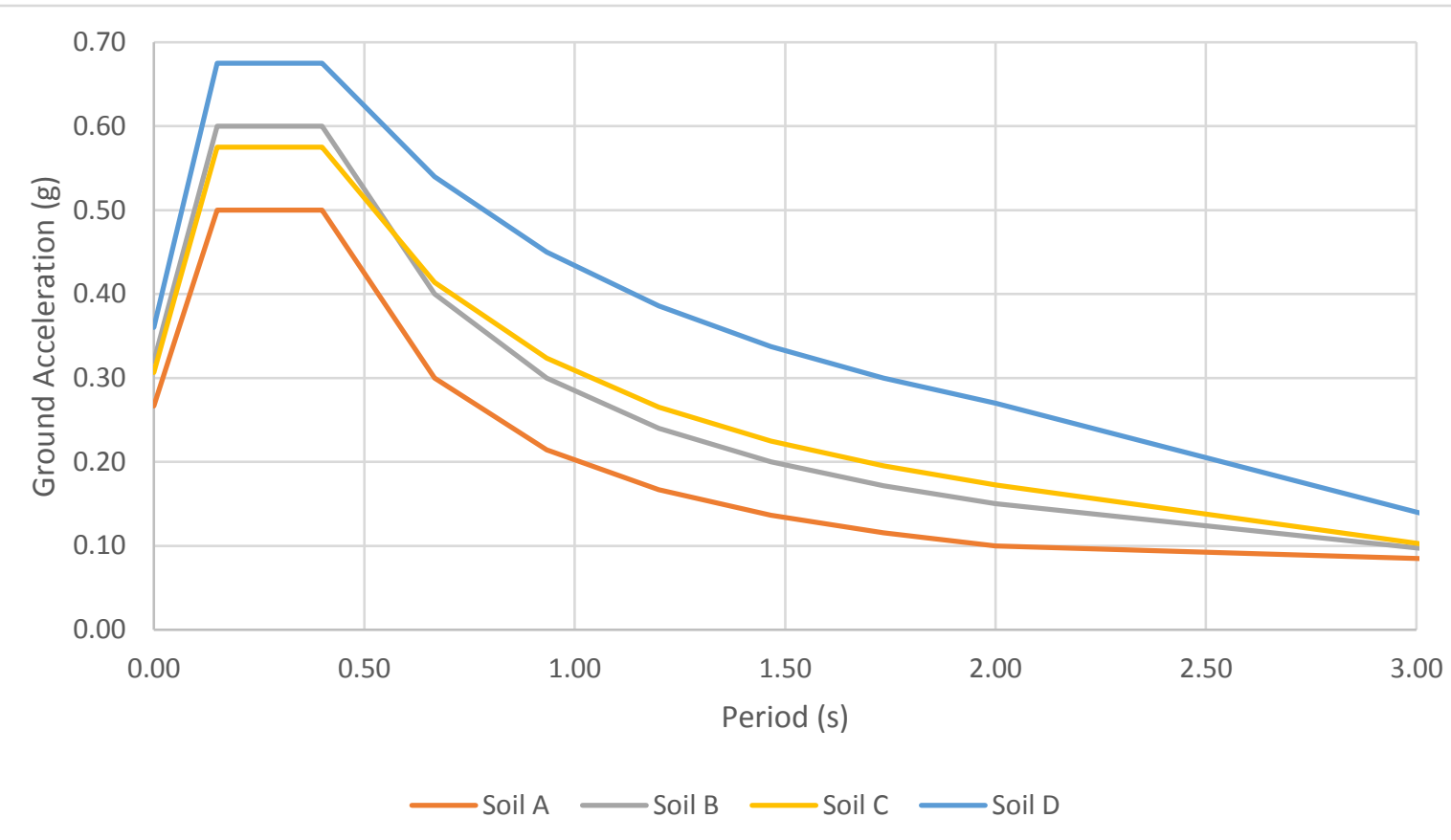

Figure 8. Design spectrums for different soil types ( $5 \%$ damping).

\section{Results and discussion}

\subsection{Capacity Spectrum Analysis}

The method that was used to determine the performance point in this study was the capacity spectrum method, also known as the acceleration - displacement response spectra method. The capacity spectrum method is a graphical and approximate method used to compare the building capacity and an earthquake demand. It was considered the seismic demand initially using a 5\% damped linear-elastic response spectrum of PGA $=0.4 \mathrm{~g}$ and thereafter a reduced spectrum to reflect the effects of energy dissipation to estimate the inelastic displacement demand. The point at which the capacity curve intersected the reduced demand curve represented a performance point at which capacity and demand were equal. As an example, Figure 9 
represents a capacity spectrum for the determination of a performance point of M-50 model capacity spectrum and demand spectrum spectral acceleration for soil type C (Eurocode 8) using SAP2000 software.

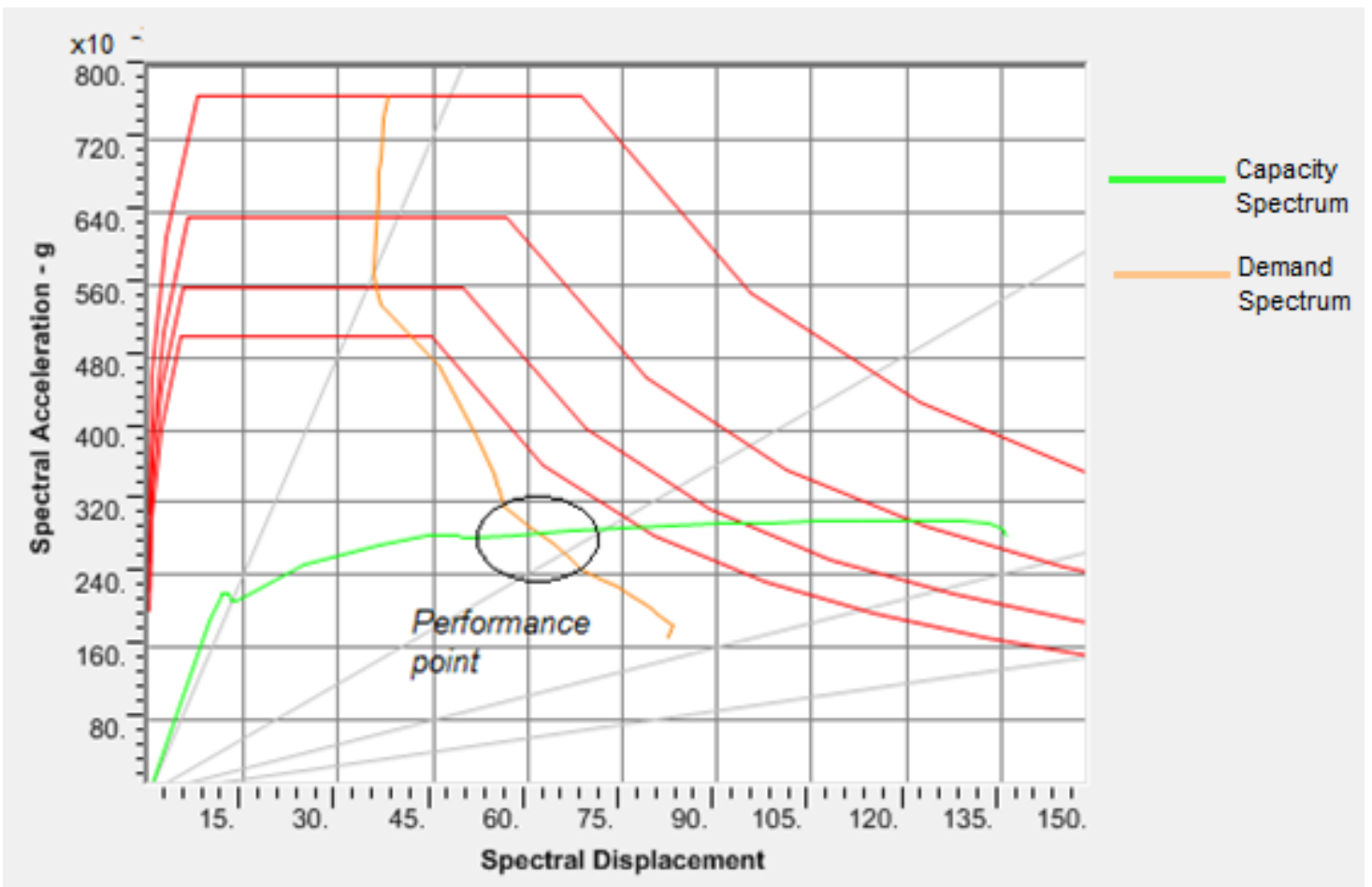

Figure 9. Performance point of M-50 capacity curve and soil type C demand spectrum.

The obtained performance points for the water towers were comparatively presented in Figure 10 and Table 5 according to the soil types. RC shafts have a very low level of ductility, thus the maximum lateral displacement (failure point) was defined at peak of base shear as this point represented the beginning of stiffness reduction. The numbers in bold show an increase (positive) or decrease (negative) percentage over the corresponding solid shaft model. These comparisons clearly showed that the soil types played a significant role in increasing top lateral displacement and stability of all models. As can be seen from Figure 10, the most dangerous was soil type D, deposits of loose-to-medium cohesionless soil, and the most favourable was soil type A, rock. All models reached a failure point earlier they could reach the performance point of soil type D.

As shown in Table 5, for all soil types, an increase in the slit width had a significant influence on the seismic performance of the water towers. For example, comparison of the base shear for soil type $\mathrm{C}$ indicated that base shear decreased by $6.7 \%, 29.8 \%$ and $48.1 \%$ for models $\mathrm{M}-50$, M-1000 and M-2000 respectively, compared to the model M-0. It is clearly seen that in wide slit shafts an increase in lateral displacement was more pronounced than a reduction in base 
shear. However, in narrow slits shafts a reduction in base shear was proportional to the increase in slit width.

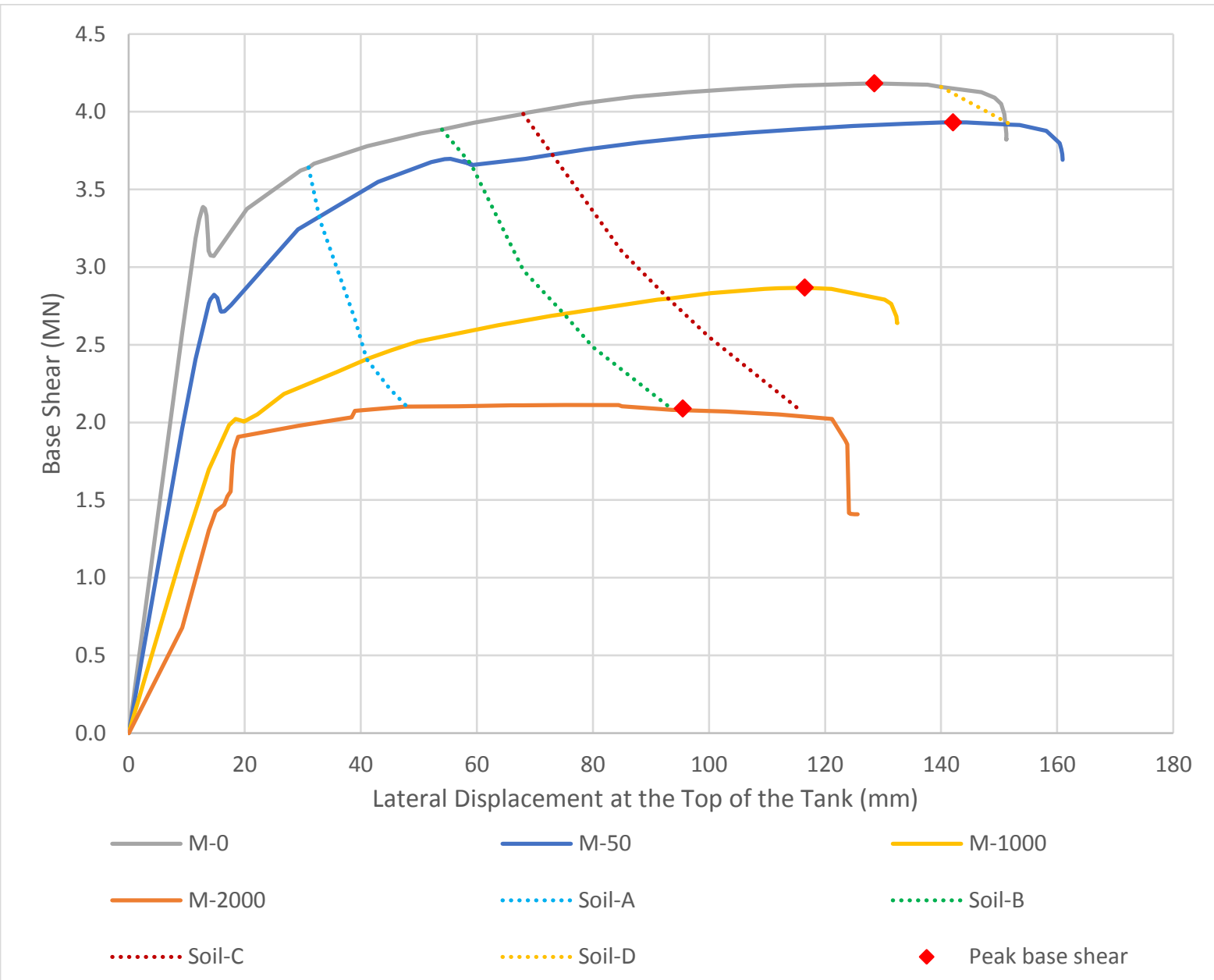

Figure 10. Results of capacity spectrum analyses.

Table 5. Results of capacity spectrum analyses.

\begin{tabular}{|c|l|l|ll|ll|ll|}
\hline & Type of Soil & M-0 & M-50 & M-1000 & \multicolumn{2}{|l|}{ M-2000 } \\
\hline \multirow{3}{*}{$\begin{array}{c}\text { Base Shear } \\
\text { Force (MN) }\end{array}$} & A & 3.64 & 3.30 & $\mathbf{- 9 . 3 \%}$ & 2.41 & $\mathbf{- 3 3 . 8 \%}$ & 2.10 & $\mathbf{- 4 2 . 3 \%}$ \\
\cline { 2 - 9 } & $\mathrm{B}$ & 3.89 & 3.66 & $\mathbf{- 5 . 9 \%}$ & 2.70 & $\mathbf{- 3 0 . 6 \%}$ & 2.10 & $\mathbf{- 4 6 . 0 \%}$ \\
\cline { 2 - 9 } & $\mathrm{C}$ & 3.99 & 3.72 & $\mathbf{- 6 . 7 \%}$ & 2.80 & $\mathbf{- 2 9 . 8 \%}$ & 2.07 & $\mathbf{- 4 8 . 1 \%}$ \\
\cline { 2 - 9 } & $\mathrm{D}$ & 3.99 & 3.72 & $\mathbf{- 6 . 8 \%}$ & N/A & & N/A & \\
\hline \multirow{3}{*}{$\begin{array}{c}\text { Top lateral } \\
\text { Displacement } \\
(\mathrm{mm})\end{array}$} & $\mathrm{A}$ & 31 & 33 & $\mathbf{+ 6 . 5 \%}$ & 41 & $\mathbf{+ 3 2 . 2 \%}$ & 48 & $\mathbf{+ 5 4 . 8 \%}$ \\
\cline { 2 - 9 } & $\mathrm{B}$ & 54 & 59 & $\mathbf{+ 9 . 3 \%}$ & 75 & $\mathbf{+ 3 8 . 9 \%}$ & 116 & $\mathbf{+ 7 0 . 6 \%}$ \\
\cline { 2 - 9 } & $\mathrm{C}$ & 68 & 73 & $\mathbf{+ 7 . 4 \%}$ & 93 & $\mathbf{+ 3 6 . 8 \%}$ & 116 & $\mathbf{+ 7 0 . 6 \%}$ \\
\cline { 2 - 9 } & $\mathrm{D}$ & 140 & 152 & $\mathbf{+ 8 . 6 \%}$ & N/A & & N/A & \\
\hline
\end{tabular}

\subsection{Stress distribution in the RC shafts}

Observation of the locations of compression and tension stress concentration can provide a better understanding of the structure's weak zones and response behaviour under seismic loads. 
According to the nonlinear properties of concrete, cracks occur across the tension regions where concrete reaches the ultimate tension strength of $\mathrm{f}_{\mathrm{t}}=2.79 \mathrm{~N} / \mathrm{mm}^{2}$ thereafter rebar carry all tension load. On the other hand, when compression stresses reach ultimate compressive concrete strength of $\mathrm{f}_{\text {cu }}=-20 \mathrm{~N} / \mathrm{mm}^{2}$, concrete begin to crash and reduce in strength, which result in failure of the water tower.

Figure 11 demonstrates the distribution of tension and compression stresses of models $\mathrm{M}-0, \mathrm{M}-$ 50 and M-1000 at the stage when base shear force reached the peak. At this stage cracks were propagated all over the $\mathrm{RC}$ shaft and the structure reached its failure point.

As expected, this behaviour was the result of stress localisation in distinct locations. Reinforced concrete did not lose strength uniformly, and the entire shaft did not simultaneously crumble under tension. Instead, steel carried the entire load across the concrete stresses reaches the ultimate value. However, until stresses in concrete did not reach the ultimate values, concrete shared the load with steel reinforcement.

The observation of stress patterns indicated variations of the stress distribution along the shaft which could result in different crack patterns in the RC shafts. According to the contours of compression and tension stress intensity, shown in Figure 11, the distribution of stresses varied between solid and slit models. In the solid model (M-0), the concentration of compressive stresses occurred at the base of the shaft and tension stresses at the lower part of the shaft.

On the other hand, two different shapes of stress pattern development were observed in slit shafts. The observed stress patterns showed that a model with narrow slits (M-50) provided the uniform distribution of the tension and compression stresses along shaft height. Compression stresses were concentrated at all connection zones. The concentration of tension stresses around coupling beams were initiated near the upper coupling beams and progressed both upwards and downwards and the ring beam was remaining elastic the longest. 


\section{Tension stress}

M-0

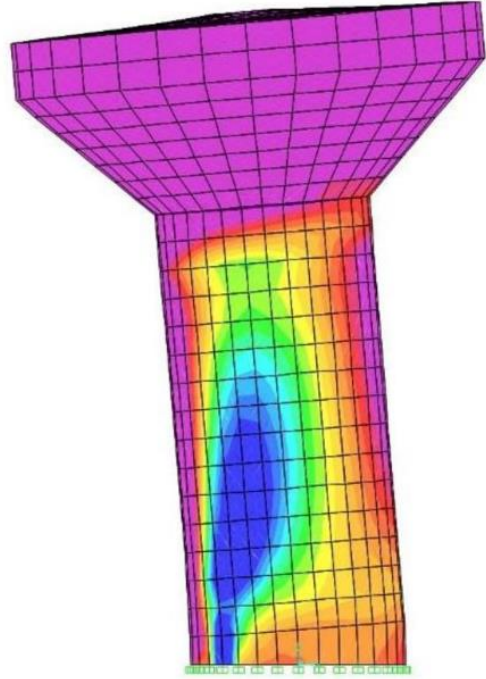

M-50

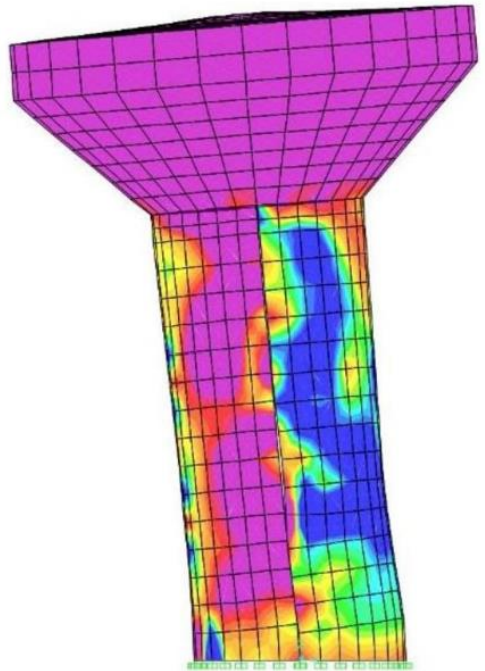

M-1000

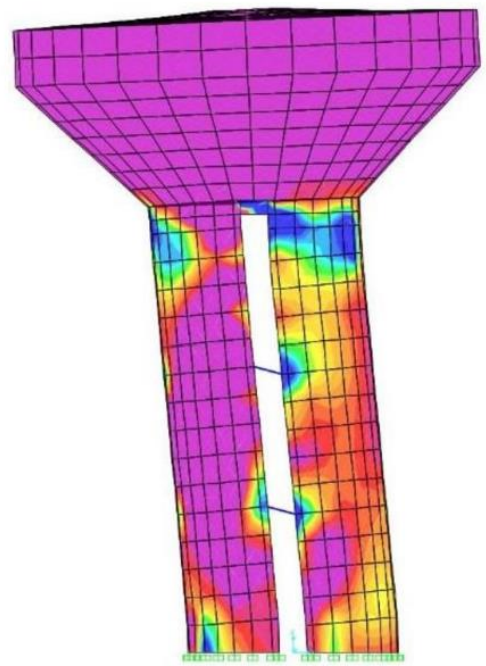

Tension stress $\left(\mathrm{N} / \mathrm{mm}^{2}\right)$

$\begin{array}{llllllllllllll}0 & 0.22 & 0.43 & 0.65 & 0.86 & 1.08 & 1.29 & 1.51 & 1.72 & 1.94 & 2.15 & 2.37 & 2.58 & 2.80\end{array}$

\section{Compresion stress}

M-0

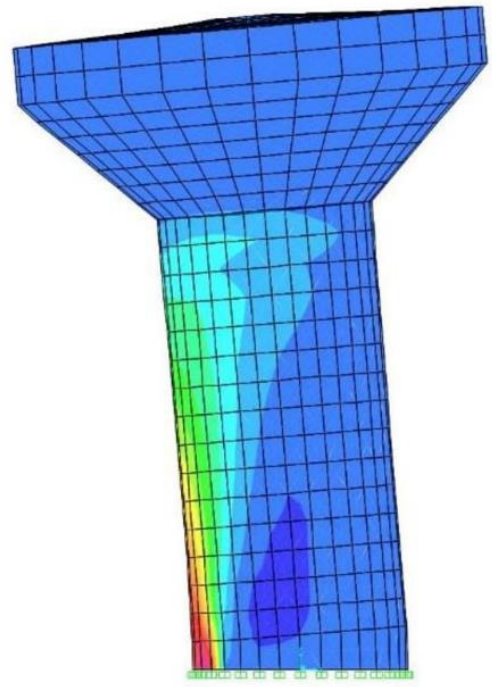

M-50
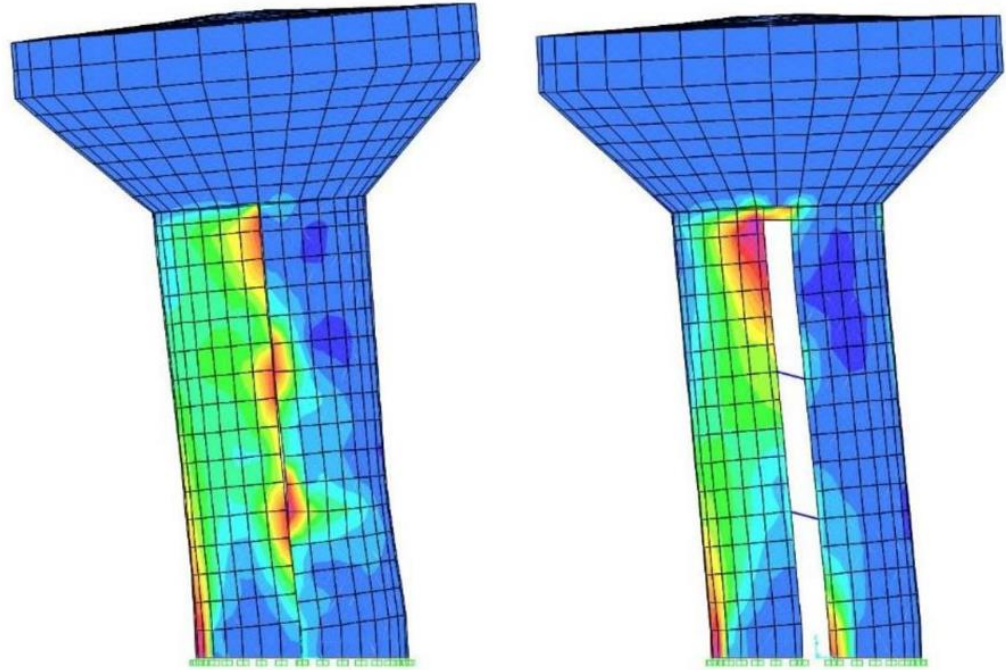

Compression stress $\left(\mathrm{N} / \mathrm{mm}^{2}\right)$

Figure 11. Contours of tension and compression stresses in RC shafts at peak base shear points of pushover analysis. 
The different distribution of stresses showed the model with wide slit width (M-1000). It can be seen that the highest tension and compression stress concentration appeared at the connection between top of the shaft and ring beam, however, there was not observed a significant compression stress concentration at coupling beams. The highest concentration of tension stresses was observed at the upper part of the shaft next to the connection to the ring beam.

In comparison between the narrow and wide slit shafts, one can see the difference between a system with narrow slits designed to work together as a coupled shaft and a system with wider slits worked as system of cantilever piers of shafts designed to work separately and connected at the top by the ring beam. As the shaft became more flexible (slit became wider), the area around coupled beams did not crack and the areas around the top ring connection began to crack at a lower base shear. As a result, the overall slit shaft capacity falls and the shaft piers crashed at a lower base shear.

The stress patterns in RC shafts were directly related to the slit width in the RC shafts. The definition of wide and narrow slits is relative and needs to be normalised.

\subsection{Concrete crash zones in the RC shafts}

In order to investigate the effect of slit width (shaft stiffness) on the distribution of compression stress, nine water tower models having different slit widths, between $50 \mathrm{~mm}$ and $2000 \mathrm{~mm}$ were considered. Five the most vulnerable zones of the compression stress concentration in the slit RC shafts were observed. The vulnerable zones included in this study (Figure 12):

- Zone I - around the shaft base corner opposite to the applied force

- Zone II - around the shaft base centre parallel to the applied force

- Zone III - around the lower coupling beam parallel to the applied force

- Zone IV - around the upper coupling beam parallel to the applied force

- Zone $\mathrm{V}$ - around the shaft top and the ring beam parallel to the applied force

This observation provided some useful information regarding the compression stress distribution along the slit shafts in the water towers that could help in obtaining an optimum slit width in the RC shaft. 


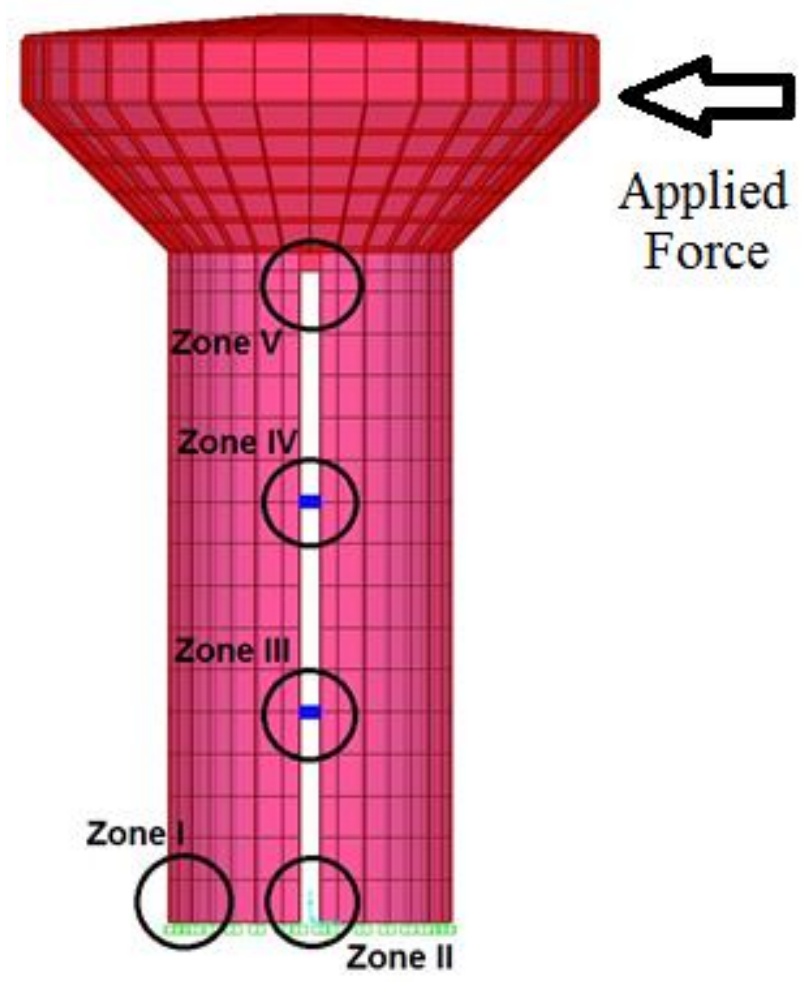

Figure 12. Vulnerable concrete crash zones in RC water towers.

Table 6 shows the compression stresses at the vulnerable zones resulted of capacity spectrum analysis designed for soil type A, B and C and seismic zone with PGA $=0.4 \mathrm{~g}$.

It can be seen from the Table 6 that compression concrete stresses in all zones did not reach the ultimate value in models with slit widths less than $500 \mathrm{~mm}$. Models with slits wider than 500 $\mathrm{mm}$ showed the high increase of the concentration of compressive stresses in zones I, II and V. Observing soil type A (Figure 13), all models with slits wider than $1000 \mathrm{~mm}$ reached compressive stresses greater than $19 \mathrm{~N} / \mathrm{mm}^{2}$ in zone $\mathrm{V}$. That can be explained by sliding effect between a water tank and a top of the shaft, which could take place in shafts with reduced stiffness by the wide slits. All models with slits narrower than $1000 \mathrm{~mm}$ did not show a dangerous stress concentration.

There was a similar compression stress distribution for soil type B (Figure 14), however all values increased and some models reached the ultimate stress values in Zone I and Zone V. It could be noticed that models M-50 and M-100 showed a compression stress distribution more uniform along the shaft height than other models in all zones.

Observation of results from soil type C (Figure 15) showed that the compression stress concentration in Zone I, II and V reached the ultimate or near ultimate values in all models 
with slit widths equal or wider than $1000 \mathrm{~mm}$ as well as model M-0 reached stresses greater than $19 \mathrm{~N} / \mathrm{mm}^{2}$ in Zone I. On the other hand, models M-50 and M-100 showed a good distribution of compression stresses along the shaft height without significant concentrations in vulnerable zones.

Table 6. Compression stress at vulnerable zones

\begin{tabular}{|c|c|c|c|c|c|c|c|c|c|c|}
\hline & \multirow[b]{2}{*}{ Zone } & \multicolumn{9}{|c|}{ FE model ID } \\
\hline & & M-0 & M-50 & M-100 & M-200 & M-300 & M-500 & M-1000 & M-1500 & M-2000 \\
\hline & & \multicolumn{9}{|c|}{ Compression stress $\left(\mathrm{N} / \mathrm{mm}^{2}\right)$} \\
\hline \multirow{5}{*}{$\frac{\square}{\bar{\Xi}}$} & I & 13.50 & 11.34 & 11.43 & 12.20 & 12.19 & 12.58 & 15.35 & 15.79 & 18.04 \\
\hline & II & 0.34 & 6.25 & 9.68 & 11.59 & 12.97 & 14.62 & 18.06 & 17.63 & 18.18 \\
\hline & III & 1.02 & 12.24 & 9.49 & 6.88 & 5.86 & 4.73 & 4.05 & 3.64 & 6.32 \\
\hline & IV & 2.38 & 12.64 & 11.08 & 9.35 & 7.24 & 6.05 & 5.50 & 4.95 & 6.81 \\
\hline & V & 3.89 & 10.83 & 12.47 & 13.92 & 14.31 & 14.68 & 19.76 & 19.72 & 20.00 \\
\hline \multirow{5}{*}{ 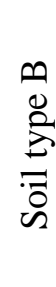 } & I & 18.20 & 15.62 & 15.73 & 16.00 & 16.04 & 16.36 & 18.40 & 19.85 & 20.00 \\
\hline & II & 0.32 & 2.57 & 5.23 & 7.95 & 10.99 & 15.73 & 19.33 & 19.40 & 18.57 \\
\hline & III & 0.30 & 16.21 & 15.74 & 10.90 & 7.75 & 5.64 & 4.35 & 2.93 & 4.36 \\
\hline & IV & 1.89 & 17.50 & 16.82 & 14.22 & 10.67 & 9.04 & 7.95 & 8.86 & 8.92 \\
\hline & V & 4.12 & 13.08 & 15.82 & 17.55 & 18.29 & 18.48 & 20.00 & 20.00 & 20.00 \\
\hline \multirow{5}{*}{ 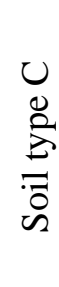 } & I & 19.39 & 16.28 & 17.07 & 17.28 & 17.50 & 18.12 & 20.00 & 20.00 & 20.00 \\
\hline & II & 0.34 & 3.21 & 3.82 & 6.91 & 8.93 & 13.49 & 19.47 & 19.28 & 20.00 \\
\hline & III & 0.21 & 13.82 & 19.21 & 13.70 & 9.73 & 6.62 & 4.89 & 3.10 & 5.09 \\
\hline & IV & 1.86 & 17.40 & 19.05 & 16.31 & 12.99 & 10.95 & 9.67 & 9.54 & 11.17 \\
\hline & $\mathrm{V}$ & 4.16 & 13.19 & 17.46 & 19.11 & 19.69 & 19.58 & 20.00 & 20.00 & 20.00 \\
\hline
\end{tabular}

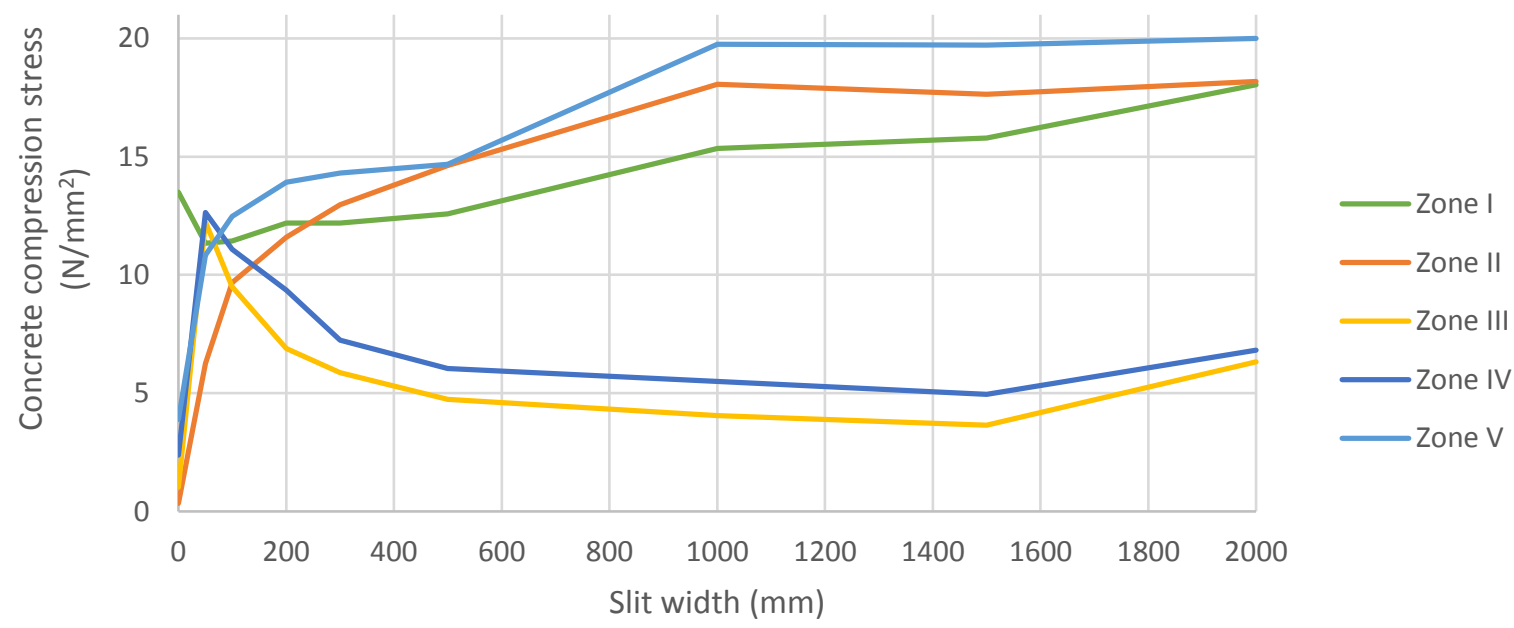

Figure 13. Slit width against concrete compression stress at vulnerable concrete crash zones in RC water towers designed for soil type A 


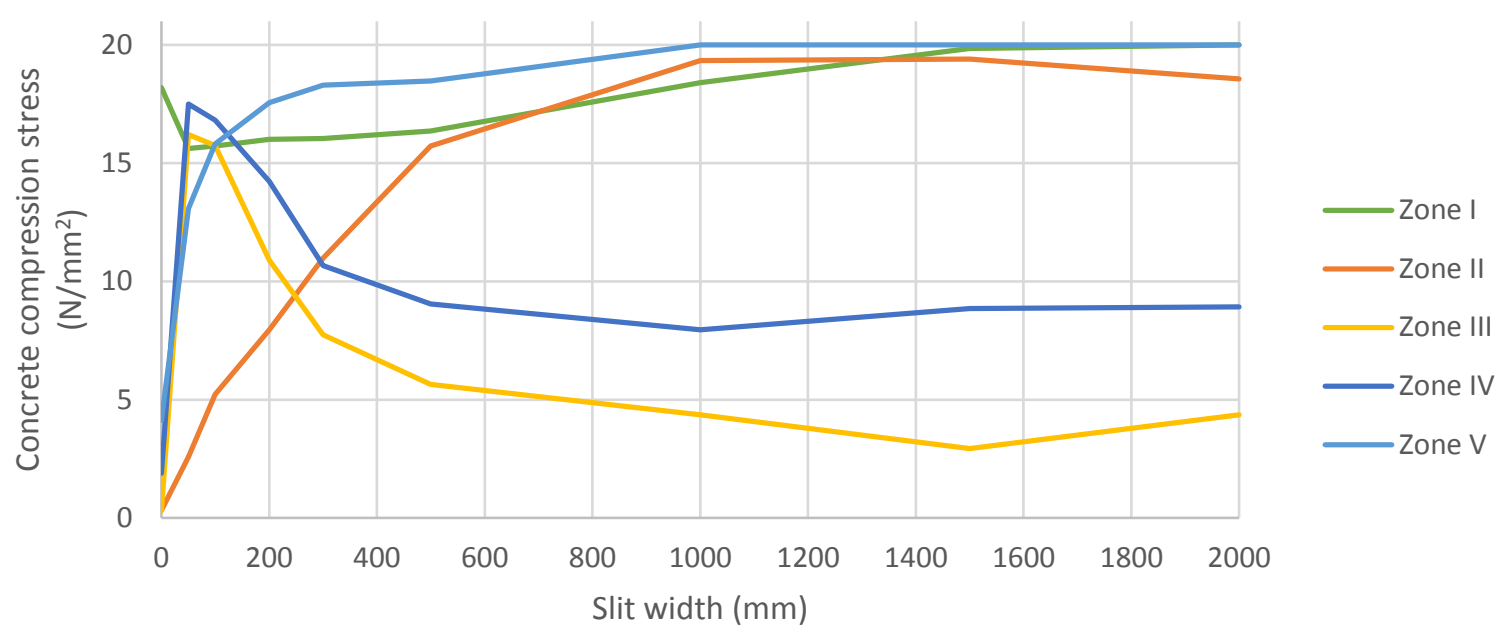

Figure 14. Slit width against concrete compression stress at vulnerable concrete crash zones in $\mathrm{RC}$ water towers designed for soil type B

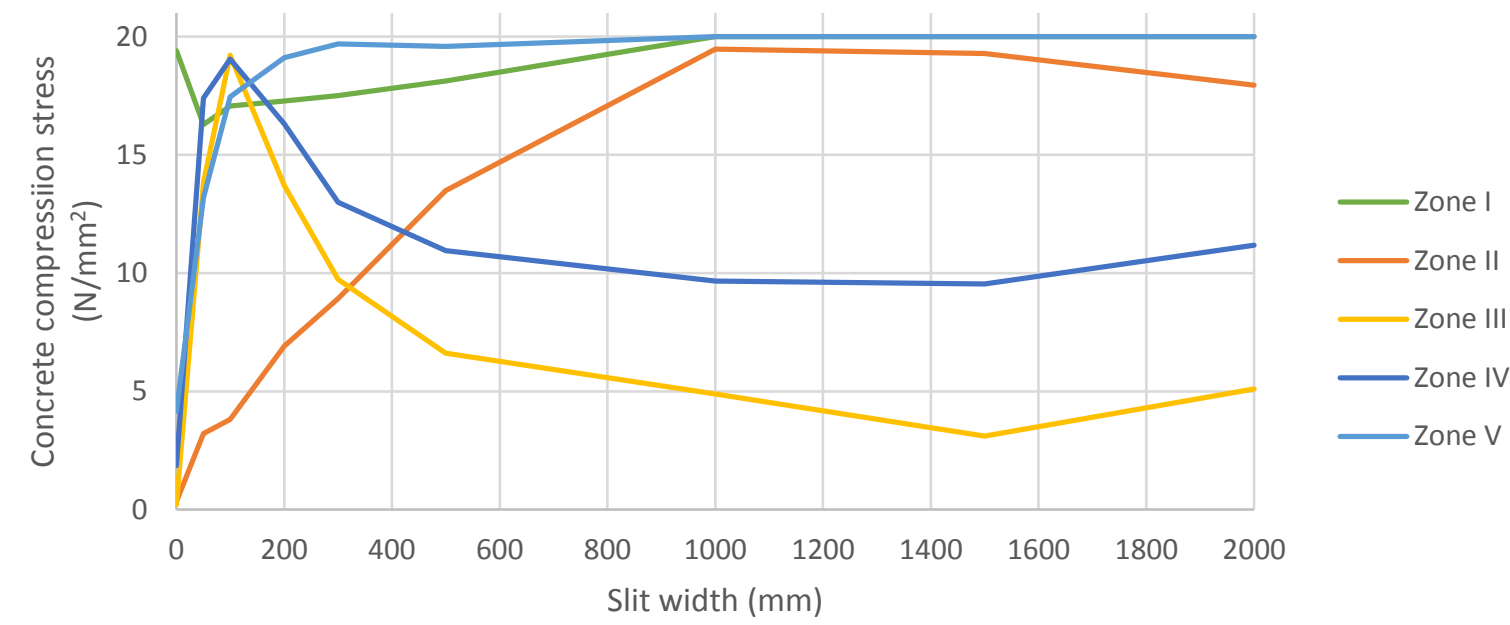

Figure 15. Slit width against concrete compression stress at vulnerable concrete crash zones in RC water towers designed for soil type $\mathrm{C}$

\section{Conclusions}

The observations of the nonlinear static and dynamic analyses would appear to justify the slit shaft system approach proposed in this work: using the slits in reinforced concrete shaft design, reduces the stress concentration at the shaft base and distributes the stresses uniformly along the shaft height. The following conclusions were drawn based on the results of this study:

The increase of the slit width in RC shafts decreased the ability to withstand an earthquake of the water towers in softer soils. That happened because of slit increase resulted to ductility increase and stiffness reduction of the RC shafts. Stiffer shafts were more appropriate for soft soils. 
Reduction in the base shear was proportional to an increase of the top lateral displacement for all soil types and models.

Soil types A, B and C identified in Eurocode 8 were appropriate for the construction of the studied water towers with slits equal to or less than 1000 millimetres with respect to a designed earthquake with PGA $=0.4 \mathrm{~g}$. However, soil type $\mathrm{D}$ was not acceptable for the construction of any type of studied models.

The most favourable for water tower construction was identified to be soil type A (rock), and the least favourable - soil type $\mathrm{C}$. The difference in top lateral displacement between soil type $\mathrm{A}$ and $\mathrm{C}$ was more than two times for all models.

Three types of contours of tension and compression stress intensity in RC shafts which may lead to the concrete cracks and crash were observed under progressive loading of pushover analysis. Firstly, the noticeable concentration of stresses near to the base was observed in the solid water tower model. Secondly, the uniform stress distribution across whole shaft height was observed in the water tower model with the narrow slit shaft. Finally, the stress concentration mostly dominated at the top of the shaft in the water tower model with the wide slit shaft.

The increase of the slit width resulted to an increase in compression stress concentration at the base and at the top of the shaft and reduction of compression stress concentration at the coupling beams.

The most effective both compression and tension stress distribution inside the RC shaft was defined to be in shafts with slit width equal to or less than 100 millimetres for all soil types.

\section{Acknowledgement}

Funding: This work was supported by Department of Engineering and the Built Environment, Anglia Ruskin University.

\section{References}

[1] Moslemi M, Kianoush MR, Pogorzelski W. Seismic response of liquidfilled elevated tanks. Journal of Engineering Structures 2011;33(6):2074-2084. 
[2] El Damatty AA, Saafan MS, Sweedan AMI. Experimental study conducted on a liquidfilled combined conical tank model. J Thin Walled Structures 2005;43:1398-417.

[3] Livaoglu R, Dogangun A. Dynamic Behavior and Seismic Performance of Elevated Tanks Due To Ground Types Defined in EC-8 and TEC-06. $1^{\text {st }}$ ECEES 2006;1313:1-9.

[4] Ghateh R, Kianoush R, Pogorzelski W. Response modification factor of elevated water tanks with reinforced concrete pedestal. Structure and Infrastructure Engineering;12(8):936-948.

[5] Rai, DC, Narayan JP, Pankaj, Kumar A. Jabalpur Earthquake of May 22, 1997: Reconnaissance Report. University of Roorkee; 1997:101.

[6] Rai DC. Review of Code design forces for shaft supports of elevated water tanks. Proceedings of 12th symposium on earthquake engineering 2002;1407-1418.

[7] Steinbrugge KV, Rodrigo FA. The Chilean earthquakes of May 1960: A structural engineering viewpoint. Bulletin Seismology American 1963;53(2):225-307.

[8] Memari AM, Ahmadi MM, Rezaee B. Behaviour of reinforced concrete water towers during Manjil-Roudbar earthquake of June 1990. Tenth World Conference on Earthquake Engineering 1992;9:4953-4953.

[9] Rai DC. Seismic retrofitting of R/C shaft support of elevated tanks. Earthquake Spectra 2002; 18:745-760.

[10] Mutoh K. A Study on Reinforced Concrete Silted Shear Walls for High-Rise Building. $5^{\text {th }}$ World Conference on Earthquake Engineering 1973;5:1135-1138.

[11] Kwan AKH, Dai H, Cheung YK. Non-Linear Seismic Response of Reinforced Concrete Slit Shear Walls. Journal of Sound and Vibration 1999;226(4):701-718.

[12] Lu X, Wu X. Study on a New Shear Wall System with Shaking Table Test and Finite Element Analysis. Earthquake Engineering \& Structural Dynamics 2000; 29(10):14251440 .

[13] Rai DC, Singh B. Seismic design of concrete pedestal supported tanks. $13^{\text {th }}$ World Conference on Earthquake Engineering 2004;230.

[14] Baetu SA, Ciongradi IP. Nonlinear Finite Element Analysis of Reinforced Concrete Slit Walls with ANSYS. Bul. Inst. Politehnic, Iasi, LVII (LXI), 1, s. Constr. Archit. 2012:3145.

[15] Kwan AKH, Dai H, Cheung YK. Elasto-plastic analysis of reinforced concrete slit shear walls. Structures and Buildings 1998;128(4):342-350.

[16] Musmar MA. Analysis of Shear Wall with Openings Using Solid65 Element. Jordan Journal of Civil Engineering 2013;7(2):164-173. 
[17] Labafzadeh MSR, Ziyaeifar M. Nonlinear Behavior of RC Dual Ductility Mode Shear Walls. AIP Conference:1020, 1854-1862.

[18] CSI. Analysis Reference Manual. Computers \& Structures, Inc. 2015.

[19] British Standards Institution. BS EN1998-4:2006: Design of structures for earthquake resistance. Part 4: Silos, tanks and pipelines. European Committee for Standardization, BSI, London; 2006.

[20] Miao ZW, Lu XZ, Jiang JJ, Ye LP. Nonlinear FE Model for RC Shear Walls Based on Multi-layer Shell Element and Microplane Constitutive Model. Computational Methods in Engineering and Science. EPMESC X, Aug. 21-23, 2006.

[21] Otani S. Nonlinear dynamic analysis of reinforced concrete building structures. Canadian J Civil Eng.1980:V7 I2. 333-344.

[22] Park R, Paulay T. Reinforced concrete structures. New York: John Wiley\& Sons, 1975.

[23] Mander JB, Priestley MJN, Park R. Theoretical Stress-Strain Model for Confined Concrete, Journal of Structural Engineering 1988;114(3):1804-1826.

[24] Holzer SM, Melosh RJ, Barker RM, Somers AE. A Computer Code for General Analysis of Two-Dimensional Reinforced Concrete Structures. Belvoir Defense Technical Information Center.

[25] ATC-40. Seismic evaluation and retrofit of concrete buildings. Redwood City: Applied Technology Council; 1996.

[26] Chopra AK, Goel RK. A modal pushover analysis procedure for estimating seismic demands for buildings. Earthquake Engineering and Structural Dynamics. 2002;31:561582.

[27] British Standards Institution. BS EN1998-1:2004: Design of structures for earthquake resistance. Part 1: General rules - Seismic action and general requirements for structures. European Committee for Standardization, BSI, London; 2004. 